\title{
Performance of carbide tools coated with DLC in the drilling of SAE 323 aluminum alloy
}

\author{
W.M. Silva ${ }^{\text {a,* }}$, L.M. Jesus ${ }^{\text {b }}$, J.R. Carneiro ${ }^{\text {b }}$, P.S. Souza ${ }^{\text {b }}$, P.S. Martins ${ }^{\text {b }}$, V.J. Trava-Airoldi ${ }^{\text {c }}$ \\ a Department of Rural Engineering, São Paulo State University, Rua José Barbosa de Barros, $n^{\circ}$ 1780, Botucatu, SP 18610-307, Brazil \\ ${ }^{\mathrm{b}}$ Department of Mechanical Engineering, Pontifical Catholic University of Minas Gerais, Av. Dom José Gaspar 500, Belo Horizonte, MG 30535-610, Brazil

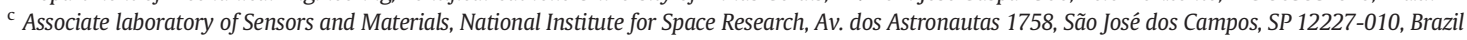

\section{A R T I C L E I N F O}

\section{Article history:}

Received 30 March 2015

Revised 25 August 2015

Accepted in revised form 7 September 2015

Available online 22 October 2015

\section{Keywords:}

Coating

Diamond-like carbon

Silicon

Adhesion

Tool

Drilling

\begin{abstract}
A B S T R A C T
The development of new coatings in the last years contributed to the improvements of machining industry. In general, it is known that the performance of drilling tools increases with the application of a proper coating, and it is worth remembering that the adhesion is an important condition for the success of any coating. This work presents a performance of cemented carbide cutting tool coated with diamond-like carbon (DLC). The deposition of the coating used in this study has been done using plasma enhanced chemical vapor deposition system. Suitable adhesion between film and the substrate did not occur in the initial deposition parameters tested. To enhance adhesion of the film, an intermediate silicon layer has been added. To evaluate this adhesion, VDI 3198 standard adhesion test was used. Spectra analyses collected using Raman backscattering spectroscopy have been used to characterize the composition and structural information of the film. The silicon layer was evaluated using atomic force microscopy. Drilling tests were performed using workpieces casting in aluminum alloy (SA-323) and roundness, radial deviation, deviation of diameter and roughness of geometries changes were measured as a function of the number of holes produced. The results showed that the DLC coating improves the tool performance, which subsequently improves the drilling quality.
\end{abstract}

(c) 2015 Elsevier B.V. All rights reserved.

\section{Introduction}

Carbon-based materials, such as diamond-like carbon (DLC) coatings, have been studied by research groups and industry over the last few decades. Amorphous carbon consists of a disordered network of carbon atoms containing a mixture of both $\mathrm{sp}^{3}$ and $\mathrm{sp}^{2}$ coordinated bonds. DLC is attributed to a variety of amorphous carbon materials, some containing up to approximately 50 at.\% hydrogen $(\mathrm{a}-\mathrm{C}: \mathrm{H})$ or containing less than 1 at.\% hydrogen $(\mathrm{a}-\mathrm{C}),[1,2]$. Possible applications of DLC include solid lubrication [3], micro-electro-mechanical devices [4] and protective coatings for automotive applications [5,6]. DLC coatings can be produced through a variety of deposition methods, such as vacuum arc discharges using a graphite cathode [7], unbalanced magnetron sputtering [8], various forms of ion implantation deposition and chemical vapor deposition $[9,10]$.

Aluminum alloys are used in many industries to make a wide range of products. Structural components made from aluminum are vital to the aerospace industry and others areas of transportation in which lightweight and strength are required [11]. Drilling aluminum alloys

\footnotetext{
* Corresponding author.

E-mail addresses: williammelosilva@gmail.com (W.M. Silva), leisianemara@yahoo.com.br (L.M. Jesus), joserub@pucminas.br (J.R. Carneiro), polianassouza@ig.com.br (P.S. Souza), paulosabara@yahoo.com.br (P.S. Martins), vladimir@las.inpe.br (V.J. Trava-Airoldi).
}

can be difficult due to the aluminum adhesion on the drill. This operation produces drill chips which adhere to the drill surface, creating obstacles to its evacuation through the drill flutes. Such chip clogging often results in rapid drill failure. The challenge is to minimize adhesion of the aluminum to the drill, which can be achieved to a certain degree using DLC coatings [12].

Coated tools have a compound material structure, consisting of substrate covered with a hard, anti-friction, chemically inert and thermal isolating layer, approximately one to a few micrometers thick. Therefore, coated tools offer better protection against mechanical loading, diminish friction and the interactions between the tool and the chips and improve the wear resistance over a wide range of cutting temperatures [13]. If we take into account that cemented carbide is widely used as a cutting tool material for its properties, including high hardness, wear resistance, excellent strength and toughness [14], DLC deposited on a carbide tool may be a good coating for drilling aluminum alloys. However, the initial problem with depositing DLCs on metal substrates is the high residual internal compressing stress within the coating, which is on the order of several GPa [15]. This limits the maximum coating thickness $(0.25 \mu \mathrm{m})$ that can be grown on metal substrates. To solve this, studies have demonstrated that thicker DLC coatings can be synthesized by incorporating interlayers [16].

In this paper, we present results of our experimental investigation of the role that DLC coating plays with respect of drill working, i.e., surface 


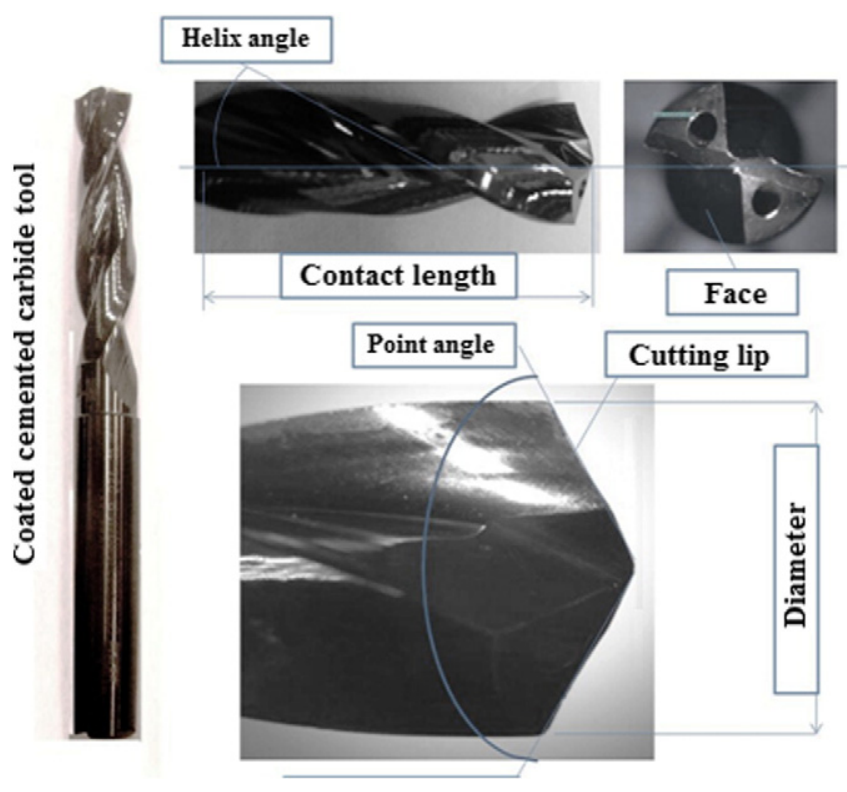

Fig. 1. Carbide-coated tool used in the experiment and drill geometry.

roundness, radial deviation, deviation of diameter and roughness during machining an SAE 323 aluminum alloy. To overcome the maximum thickness limitation of DLC, we deposited a silicon layer on the tool substrate prior to the DLC deposition. The intent of the interlayer is to produce a graded interface, beginning with the carbide substrate, followed by the DLC coating. Such a graded interface decreases the interfacial free energy [17], increasing the work required for delamination and improving the DLC coating adhesion. Moreover, the gradual transition from carbide to DLC through an intermediate silicon layer reduces the thermal expansion coefficient mismatch at the DLCsubstrate interface and, thus, the thermal stress.

\section{Experimental procedure}

The cutting tools used in this work for drilling were $7.5 \mathrm{~mm}$ diameter carbide twist drills manufactured by Nipo-Tec Ind. Co. The coated drill consists of two flutes with a helix angle of $36^{\circ}$, a point angle of $130^{\circ}$ and a contact length of $45 \mathrm{~mm}$, as shown in Fig. 1. The drills were degreased in an ultrasonic bath before being placed in the deposition chamber. After evacuation to less than $1 \times 10^{-4} \mathrm{~Pa}$, argon was introduced into the chamber at a pressure of $15 \mathrm{~Pa}$ and the tools were plasma cleaned for $15 \mathrm{~min}$. All surface depositions were performed using pulsed DC plasma enhanced chemical vapor deposition system. The tools were mounted on a water-cooled $50 \mathrm{~mm}$ diameter cathode, which was biased by an asymmetrical bipolar pulsed DC source consisting of a fixed positive pulse amplitude of $30 \mathrm{~V}$ followed by a variable negative

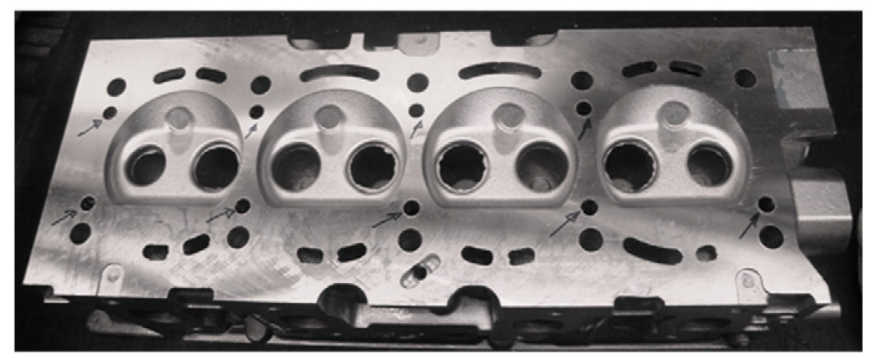

Fig. 2. One of the two hundred workpieces used for the experiment. The workpiece consists of a cylinder head die cast SAE 323 aluminum alloy. The arrows indicate the nine holes drilled by the tools used in this work.
Table 1

Chemical composition of die cast aluminum SAE 323

\begin{tabular}{cllllllll}
\hline Element & $\mathrm{Cu}$ & $\mathrm{Fe}$ & $\mathrm{Mg}$ & $\mathrm{Mn}$ & $\mathrm{Ni}$ & $\mathrm{Si}$ & $\mathrm{Zn}$ & $\mathrm{Sn}$ \\
\hline wt.\% & $3.0-4.0$ & $<1.3 \%$ & $<0.10$ & $<0.50$ & $<0.5$ & $7.5-9.0$ & $<3.0$ & $<0.35$ \\
\hline
\end{tabular}

pulse with peak amplitude ranging from -250 to $-900 \mathrm{~V}$ at $20 \mathrm{kHz}$. The surface preparation for film deposition consisted of two steps: (1) the thin amorphous silicon interlayer was deposited using pure silane as the reactive precursor gas. Si-film was deposited using total gas pressure of $10 \mathrm{~Pa}$ with gas flow rate of $10 \mathrm{sccm}$ for $0.5 \mathrm{~h}$ at $460^{\circ} \mathrm{C}$; (2) the DLC was deposited using pure methane at $40 \mathrm{~Pa}$ and $150^{\circ} \mathrm{C}$ for $1.5 \mathrm{~h}$. Different pressures are required for plasma stability to prevent sparks.

We used a Renishaw 2000 Raman system with Ar-ion laser (wavelength $=514 \mathrm{~nm}$ ) in the backscatter geometry to obtain the Raman spectra of the carbon film. Spectral fitting was performed using two Gaussian functions to obtain the $\mathrm{I}_{\mathrm{D}} / \mathrm{I}_{\mathrm{G}}$ intensity ratio of $\mathrm{G}$ and $\mathrm{D}$ bands. Images were obtained using scanning electron microscopy (Hitachi S-3400 VP-SEM). Geometries changes of the holes were measured using a coordinate three-dimensional machine. The surface roughness was analyzed via the $R_{a}$ factor and measured with contacting stylus equipment.

For the purposes of our experiments, a quantity of two hundred die cast aluminum alloy (SAE 323) was used as the workpiece. The arrows in Fig. 2 indicate the nine holes drilled. The chemical composition of SAE 323 is shown in Table 1. According to the manufacturer, the mechanical properties of this alloy are ultimate tensile strength: $324 \mathrm{MPa}$, yield tensile strength (at 0.2\%): $159 \mathrm{MPa}$, elongation at break: 3.5\%, modulus of elasticity: $71 \mathrm{GPa}$, Poisson's ratio: 0.33 and Hardness: $80 \mathrm{HB}$. The melting point is $538-593^{\circ} \mathrm{C}$ and the density is $2.76 \mathrm{~g} / \mathrm{cm}^{3}$. Micro structure of the alloy consisted of an $\alpha-\mathrm{Al}$ matrix and eutectic silicon particles, and the intermetallic phases are $\mathrm{Al}_{5} \mathrm{Cu}_{2} \mathrm{Mg}_{8} \mathrm{Si}_{6}, \mathrm{Al}_{15}(\mathrm{Fe}, \mathrm{Mn})_{3} \mathrm{Si}_{2}$ and $\mathrm{CuAl}_{2}$.

The drilling tests were performed using a computer numerically controlled (CNC) drill press with an external Minimum Quantity Lubrication (MQL) system and performed at a cutting speed of $217 \mathrm{~m} / \mathrm{min}$, $11,500 \mathrm{rpm}$, using a feed rate of $0.25 \mathrm{~mm} / \mathrm{rev}$. The standard produced holes have diameter of $7.5 \mathrm{~mm}$ and a depth of $16 \mathrm{~mm}$. Hole quality of each specimen was determined by measuring the hole size, roundness, radial and diameter deviation and roughness. Moreover, uncoated tools were also used to provide a baseline for comparing the results.

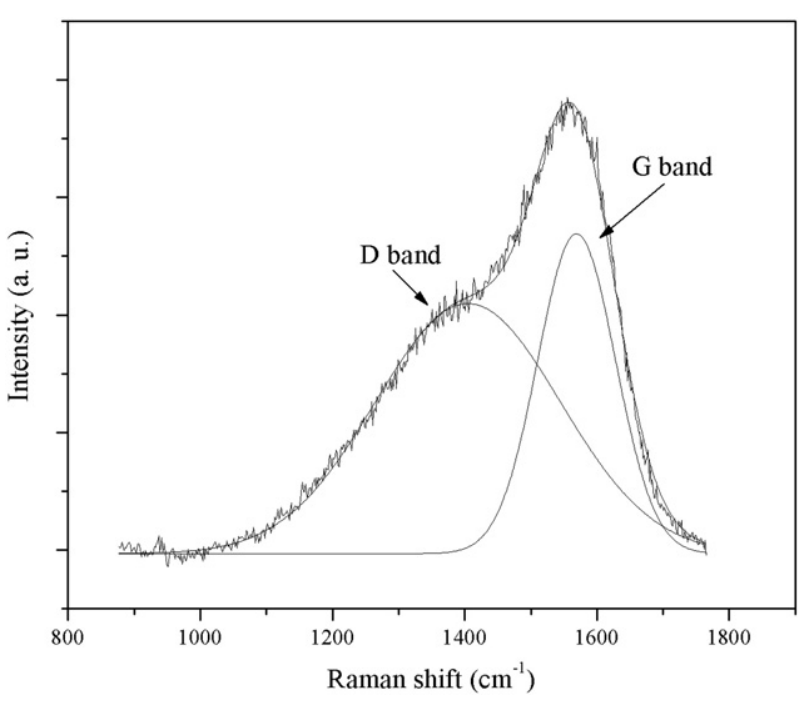

Fig. 3. Raman spectrum of the DLC film where the D and G bands have been used to characterize the composition and structural information of the film. 
Table 2

Comparison of the D and G bands characteristics between the DLC films deposited on the tool samples.

\begin{tabular}{|c|c|c|c|c|}
\hline \multirow{2}{*}{ Sample } & \multicolumn{2}{|c|}{ Band position $\left(\mathrm{cm}^{-1}\right)$} & \multirow{2}{*}{$\frac{\text { FWHM }\left(\mathrm{cm}^{-1}\right)}{\mathrm{G}}$} & \multirow{2}{*}{$\mathrm{I}_{\mathrm{D}} / \mathrm{I}_{\mathrm{G}}$} \\
\hline & D & G & & \\
\hline 1 & 1383.3 & 1555.2 & 118.3 & 0.65 \\
\hline 2 & 1382.1 & 1555.5 & 117.7 & 0.63 \\
\hline 3 & 1385.8 & 1557.4 & 117.1 & 0.65 \\
\hline 4 & 1382.8 & 1558.0 & 117.1 & 0.62 \\
\hline
\end{tabular}

\section{Results and discussion}

The material of the tool consists of three dimensional carbide tungsten grains with cobalt as a binder phase matrix [18]. No thermal diffusion treatment was carried out on the tool before the deposition of the DLC. Diamond-like carbon is defined as an amorphous carbon with a significant fraction of $\mathrm{sp}^{3}$ bonds, and the films produced here are known as hydrogenated amorphous carbon or sputtered $\mathrm{a}-\mathrm{C}$. The film deposited on the tools has similar spectrum to the work done by A. Ferrari and J. Robertson (2004). They measured the $\mathrm{sp}^{3}$ content by nuclear magnetic resonance and their model establish a relation between visible Raman (514 nm) parameters and $\mathrm{sp}^{3}$ content. In this sense, quantitative evaluation of the fraction of $\mathrm{sp}^{2}$ bonds in the coating was performed based on the Raman spectroscopy data. All the different types of carbon exhibit common features in the Raman spectra from 800 to $2000 \mathrm{~cm}^{-1}$. Usually, the most important bands observed are the $\mathrm{D}$ and $\mathrm{G}$ peaks, which lie at 1560 and $1360 \mathrm{~cm}^{-1}$, respectively. It is known that the $\mathrm{D}$ and $\mathrm{G}$ peaks are due to the resonant process of $\mathrm{sp}^{2}$ sites. The $\mathrm{G}$ peak is due to bond stretching in all the pairs of $\mathrm{sp}^{2}$ atoms located in the crystal lattice (in both the rings and chains), whereas $\mathrm{D}$ peak is due to the breathing modes of the $\mathrm{sp}^{2}$ atoms in the rings. The corresponding Raman spectrum in Fig. 3 was fitted using two Gaussian distribution functions according to A. Ferrari and J. Robertson (2004), in which $\mathrm{D}$ and $\mathrm{G}$ bands matched the energy preferentially excited.

Dispersion of $G$ peak at approximately $1550 \mathrm{~cm}^{-1}$ is identified as disordered graphite which is used to distinguish any samples with similar Raman spectrum [19]. Thus, the intensity ratio of the D and G peaks $\left(\mathrm{I}_{\mathrm{D}} / \mathrm{I}_{\mathrm{G}}\right)$, the $\mathrm{G}$ band peak position and its full width at half maximum (FWHM) were also evaluated. The spectra collected exhibited the followed Raman parameters, as shown in Table $2: \mathrm{I}_{\mathrm{D}} / \mathrm{I}_{\mathrm{G}}=0.63$ $( \pm 0.01), \mathrm{FWHM}=117.6( \pm 0.5)$ and the $\mathrm{G}$ peak center is at 1556.5 $( \pm 1.4) \mathrm{cm}^{-1}$. Mechanical properties of the film like hardness and Young modulus are related to the $\mathrm{I}_{\mathrm{D}} / \mathrm{I}_{\mathrm{G}}$. DLCs harder than the coating used in this work (with lower $\mathrm{I}_{\mathrm{D}} / \mathrm{I}_{\mathrm{G}}$ ) have too much intrinsic stress leading to delamination. Thus, the results are in the limit of the load carrying capacity of the film $[20,21]$.

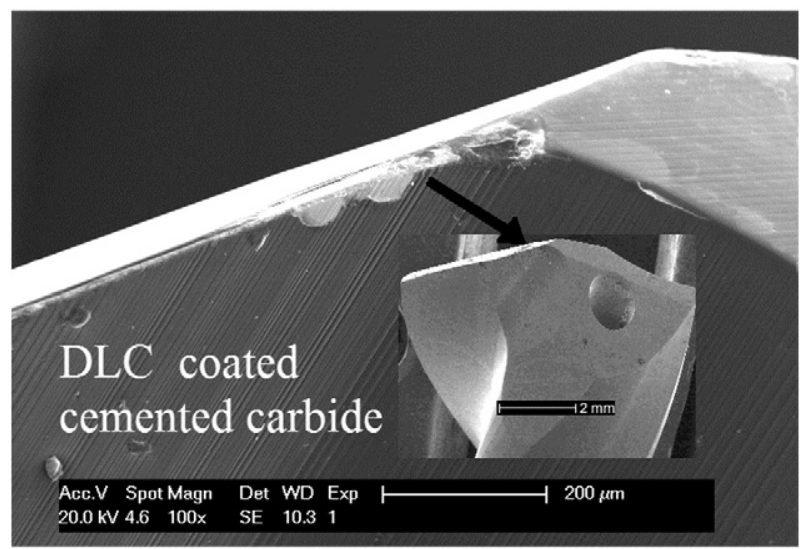

Fig. 4. SEM of the DLC-coated cemented carbide. The arrow indicates the tip of the drill where the DLC film was not fully adhered to the tool. This image was obtained before any test.

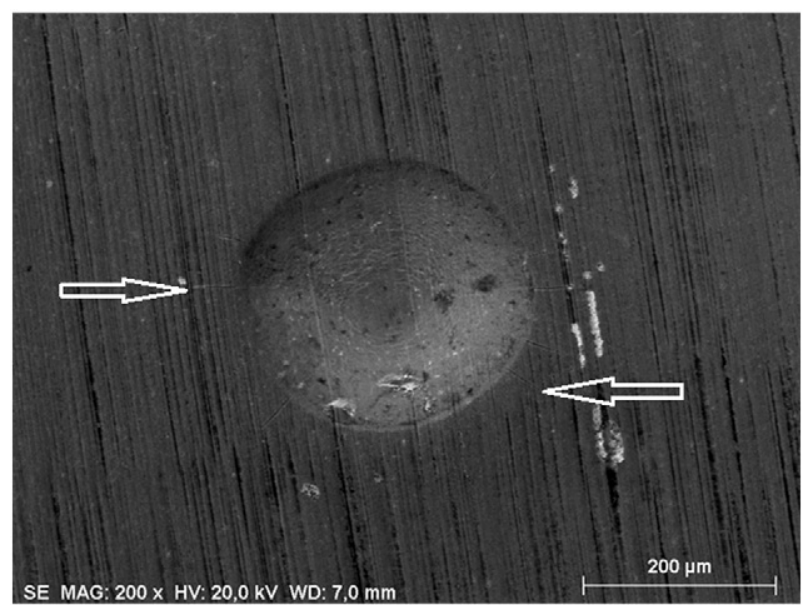

Fig. 5. SEM of the DLC on carbide substrate after adhesion test. The arrows indicate small cracks of the coating. According to the VDI 3198 standard, the coating has satisfactory adhesion.

Fig. 4 shows a SEM image of the coated cemented carbide with DLC coating. One issue with DLC on metal is its low adhesion due the high residual compressing stress, which is on the order of several GPa [22]. Thus, a silicon layer was used to reduce the thermal stress and improve the adhesion of the DLC film to the substrate. The silicon layer did not full support the high residual compressing stress generated between metal substrate and DLC on the edge of the drill. Therefore, the detachment of the small part of the film occurred shortly after deposition, likely during cooling After dozens of unsuccessful deposition tests on tool due failure of the film on the edges, it was found that the geometry of the substrate has a significant influence on the film adhesion. In this way, the deposition condition was optimized to get a coated tool in which was possible its use in drilling. The major advantage achieved here is that DLC film was obtained with high degree of adhesion in a flat surface, as showed in Fig. 5. The arrows in Fig. 5 indicate the small cracks, and according to the principle of the VDI 3198 indentation test, the film has high adhesion and it is classified as acceptable failure [23]. Cross-section image by atomic force microscopy

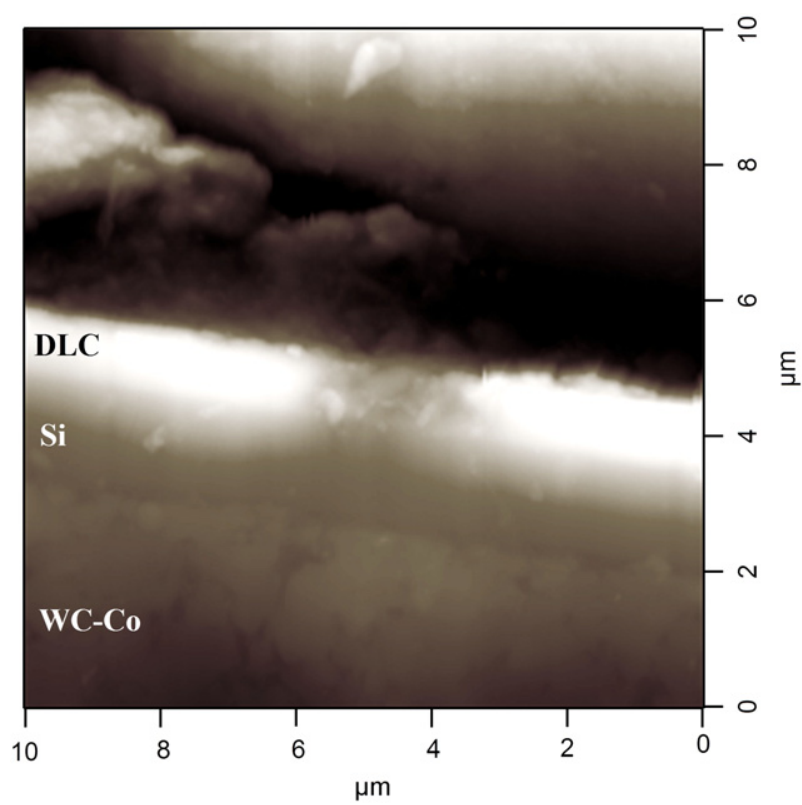

Fig. 6. From the atomic force microscopy was possible to obtain the cross section image of coating and the substrate. The interlayer of Si is indicated, as well the DLC film and carbide substrate. 

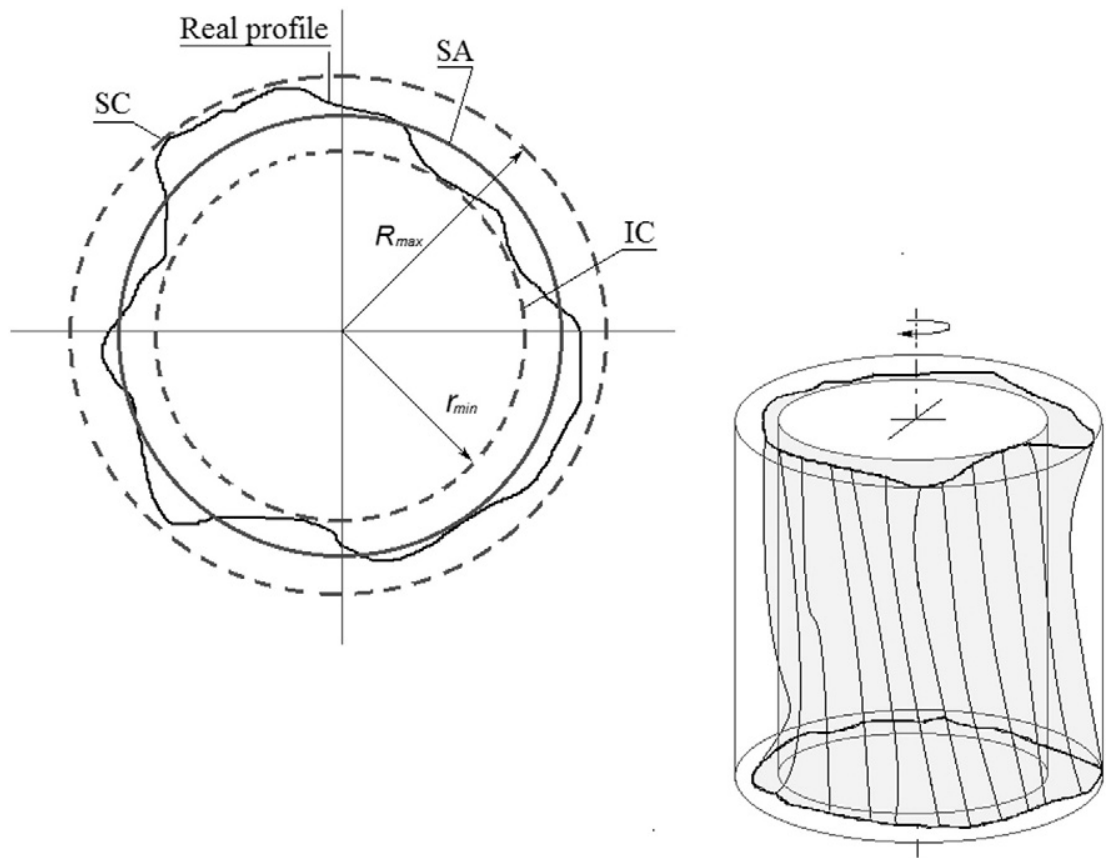

Fig. 7. Sample showing an example of the measured roundness result.

in Fig. 6 shows the substrate (WC-Co), the silicon layer (Si) and the DLC coating, respectively.

One of the most important fundamental forms for engineering components is a circular cross-section. As an example, Fig. 7 shows the roundness measurement of the hole produced by the coated tool, where the difference between the real profile and the references from a surrounding circle (SC), square average (SA) and inscribed circle (IC) are shown. The maximum $\left(R_{\max }\right)$ and minimum $\left(r_{\min }\right)$ are the radii of the SC and IC, respectively. The roundness is calculated by $R_{\max }-R_{\min }$. These references are fixed around the circular profile and downhole to form the radial deviation. The expression to calculate the radial deviation derives from the difference between the surrounding and inscribed cylinders into the hole length, i.e., $\left(R_{\max }-R_{\min }\right) / 2$ [11].

Fig. 8 shows the effect of the DLC coating on the roundness of the drilled hole as a function of the hole number. The coated tool demonstrated a better performance when compared with the uncoated

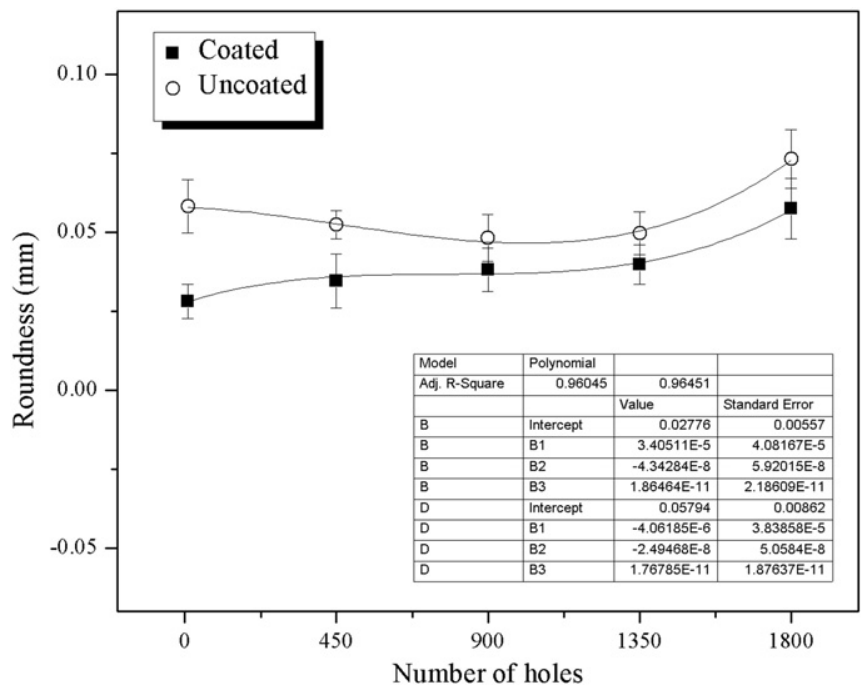

Fig. 8. Evaluation of the roundness as a function of the number of holes produced using the coated and uncoated tools. tool. After 1800 holes, both tools exhibited an increased roundness error due to the vibration during the drilling operation. The vibration was caused by the excess of aluminum against the rake face, forming built up edges. The radial deviations exhibited a similar trend to the roundness, as shown in Fig. 9. Smaller values of the radial deviations are observed for the coated tool because DLC provides a lower friction coefficient between the tool and the workpiece.

The difference between the entry and the bottom of the hole is known as the deviation of diameter. This effect occurs when there are vibrations at the drill in its first touch. In addition, spring back can occur because of the elastic deformation of the workpiece material during the movement of the drill. Fig. 10 shows the coating effect on the deviation of diameter. The holes drilled using the coated tool have low deviations only on the first hole; the deviation of diameter changes from 0.07 to $0.08 \mathrm{~mm}$ as the number of holes increases. The effect of hole clogging is reduced when a coated tool is used. This behavior

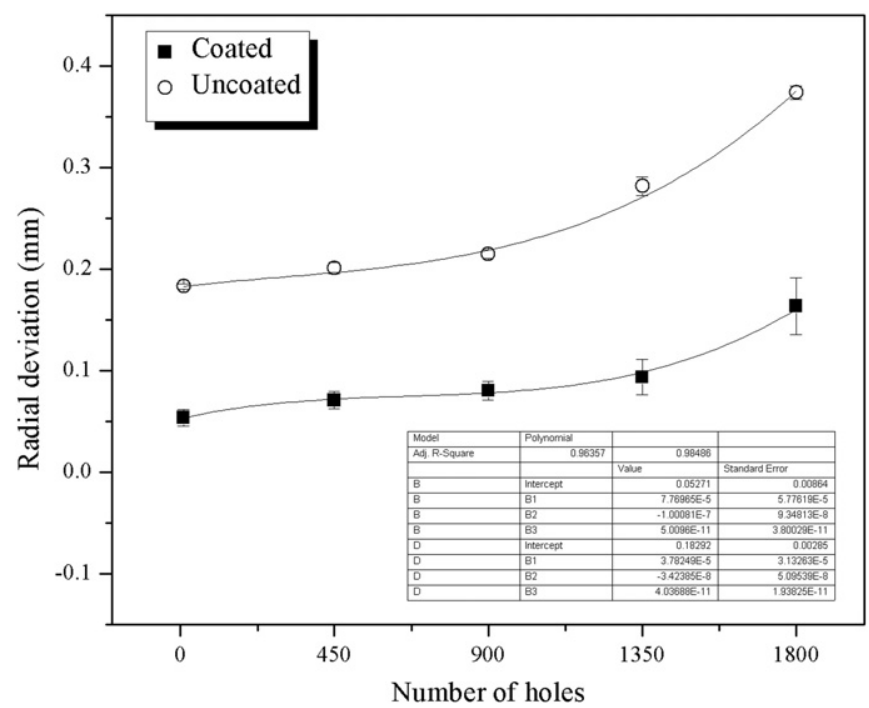

Fig. 9. Evaluation of the radial deviation as a function of the number of holes produced using coated and uncoated tools. 


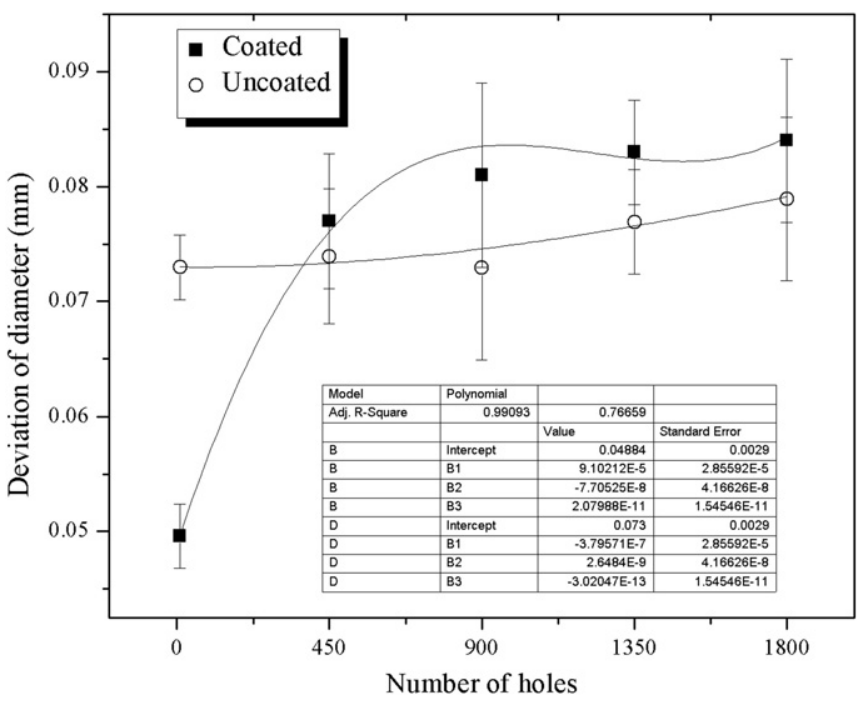

Fig. 10. Evaluation of the deviation of diameter as a function of the number of holes produced using coated and uncoated tools.

may explain the differences in the bottom diameter of the hole and why the entry diameter decreased [11].

Fig. 11 shows the roughness of the holes calculated by the expression $R_{a}=\frac{1}{l} \int_{0}^{l} f(x) d x$, where $l$ is the sampling length of the profile and $f(x)$ is the functional form of the profile heights measured from a reference line. The DLC-coated tool yielded a low roughness for all 1800 holes due its low surface roughness (under $7 \mu \mathrm{m}$ ). However, the uncoated tool machined up to 1350 holes with satisfactory performance. Beyond that, the roughness of the hole tends to increase considerably.

Fig. 12 exhibits both flank and crater wear forms of the coated tool after drilling 1800 holes. The inside surface parts with DLC remained on the tool and the flank wear is most evident due to contact between the workpiece and the cutting edge. The crater wear occurred due to the breaking of chips on the rake face, besides a uniform flank wear is evident in Fig. 12. The tool wear occurred mainly at the cutting edge where the DLC films did not remain adhered. DLC can work properly to a certain number of holes, leading to abrasive wear at the cutting

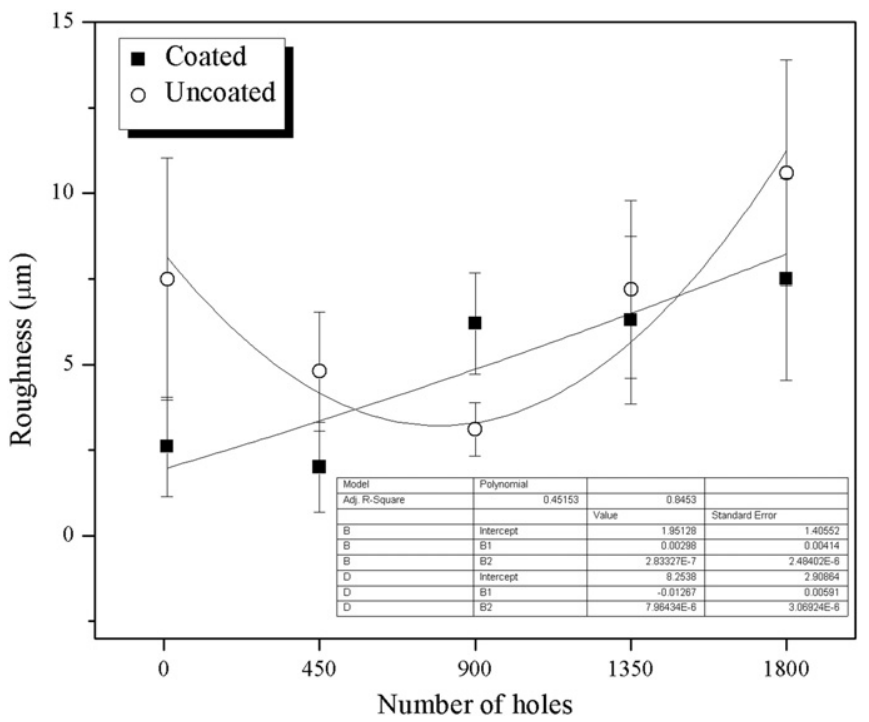

Fig. 11. Evaluation of the roughness as a function of the number of holes produced using coated and uncoated tools.

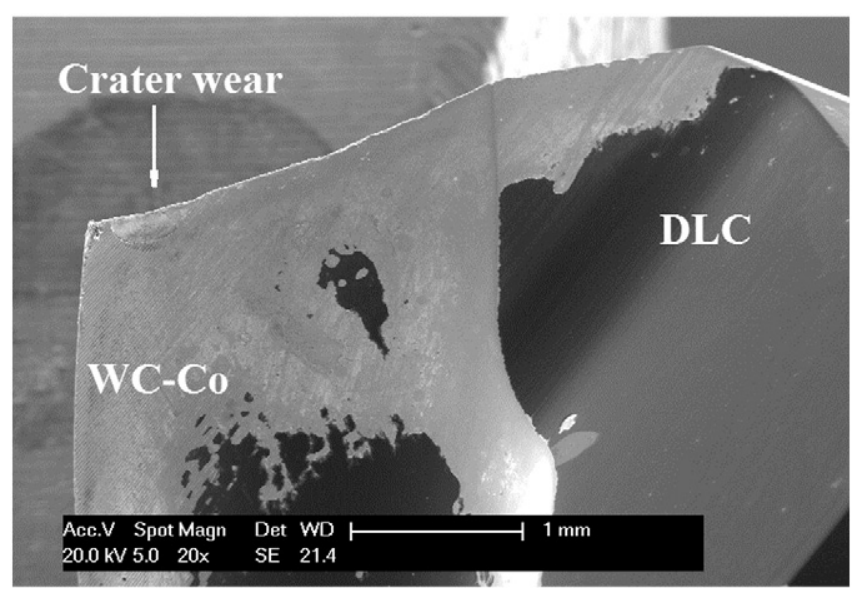

Fig. 12. Front view of the drill after working on 1800 holes. DLC was removed close to the cutting edge, however some parts of the film has been maintained to the tool surface.

edge of the drill and resulting in further coating losses. Fig. 13 shows the path of the wear (indicated by arrows). This demonstrates that the adhesive properties of the film to the substrate are able to withstand the high loading experienced during the drilling process [24]. The uncoated tools have demonstrated high wear on all the cutting edge. Fig. 14 shows the tool edge break after 1800 holes in which the cutting edge was totally removed.

\section{Conclusions}

The deposition of the DLC film on the tools surface exhibited deposition defects at parts of the cutting edges. In an effort to make a film with high adhesion between the film and substrate, a silicon interlayer was successfully incorporated. The DLC coating improved the hole quality. The roundness curves and radial deviation for the coated tools achieved better performance when compared with the uncoated tools, as such the deviations of diameter. The roughness produced by the uncoated tools increased significantly. Likely, the DLC mechanical properties such as high hardness and reduced friction were the main factors for the performance of the coating. Finally, the use of cemented carbide drills with DLC can be a good solution when drilling aluminum alloys at high speeds.

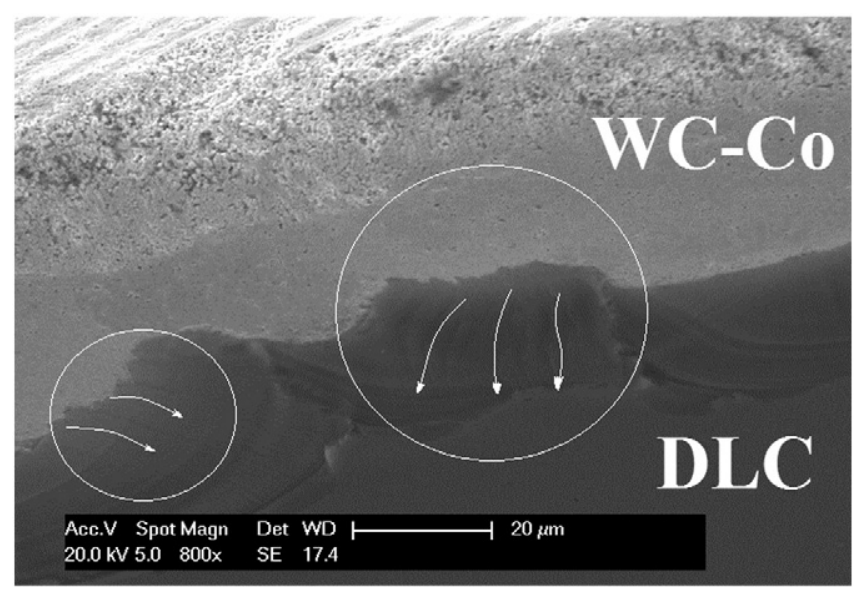

Fig. 13. SEM of the drill edge after working on 1800 holes. The DLC film was fully worn on the flank face. However, it remained adhered to the secondary surface of the tool. Wear path of the film is indicated by arrows. 


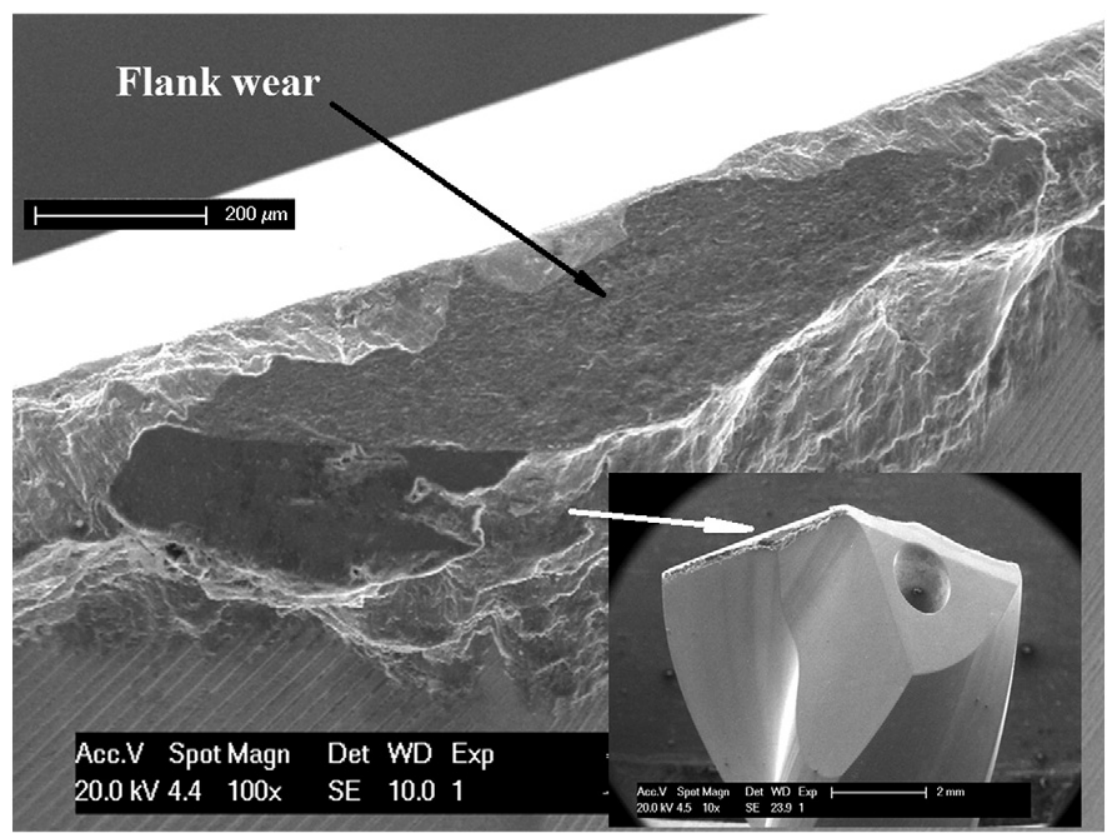

Fig. 14. Image of uncoated tool after drilling of 1800 holes. All cutting edge was removed by the effect of abrasion during the drilling.

\section{Acknowledgments}

The financial support of FAPESP (Process $n^{\circ} 2015 / 00671-8$ ) is gratefully acknowledged. WMS would like to thank the help of Prof. Dr. Claudinei José de Oliveira from PUC Minas and Sr. João Isamu Arakaki from Nipo-Tec.

\section{References}

[1] A. Grill, Diam. Relat. Mater. 8 (1999) 428-434.

[2] J. Vetter, Surf. Coat. Technol. 257 (2014) 213-240.

[3] A. Vanhulsel, F. Velasco, R. Jacobs, L. Eersels, D. Havermans, E.W. Roberts, I. Sherrington, M.J. Anderson, L. Gaillard, Tribol. Int. 40 (2007) 1186-1194.

[4] A.P. Mousinho, R.D. Mansano, M. Massi, J.M. Jaramillo, Diam. Relat. Mater. 12 (2003) 1041-1044.

[5] P. Mutafov, J. Lanigan, A. Neville, A. Cavaleiro, T. Polcar, Surf. Coat. Technol. 260 (2014) 284-289.

[6] K. Komori, N. Umehara, Tribol. Int. 84 (2015) 100-109.

[7] H. Fukui, J. Okida, N. Omori, H. Moriguchi, K. Tsuda, Surf. Coat. Technol. 187 (2004) $70-76$.
8] S. Bhowmick, A. Banerji, A.T. Alpas, Surf. Coat. Technol. 260 (2014) 290-302.

[9] W. Enzinger, Surf. Coat. Technol. 203 (2009) 2721-2726.

[10] G. Capote, L.F. Bonetti, L.V. Santos, V.J. Trava-Airoldi, E.J. Corat, Thin Solid Films 516 (2008) 4011-4017.

[11] M. Kurt, Y. Kaynak, E. Bagci, Int. J. Adv. Manuf. Technol. 37 (2008) 1051-1060.

[12] S. Bhowmick, A.T. Alpas, Int. J. Mach. Tools Manuf. 48 (2008) 1429-1443.

[13] K. Bousakis, N. Michailidis, G. Skordaris, E. Bousakis, D. Biermann, R. M'Saoubi, CIRP Ann. Manuf. Technol. 61 (2012) 703-723.

[14] W. Ze, D. Jianxin, X. Youqiang, C. Hongwei, Z. Jun, Mater. Des. 41 (2012) 142-149.

[15] K. Chen, J. Lin, Thin Solid Films 517 (2009) 4916-4920.

[16] C. Chang, D. Wang, Diam. Relat. Mater. 10 (2001) 1528-1534.

[17] J.W. Cahn, J.E. Hilliard, J. Chem. Phys. 28 (1958) 258-267.

[18] D. Thakur, B. Ramamoorthy, L. Vijayaraghavan, Mater. Lett. 62 (2008) 4403-4406.

[19] F. Tuinstra, J.L. Koenig, J. Chem. Phys. 53 (1970) 1126-1130.

[20] A. Ferrari, Diam. Relat. Mater. 11 (2002) 1053-1061.

[21] A. Ferrari, J. Robertson, Philos. Trans. R. Soc. Lond. A 362 (2004) 2477-2515.

[22] W.M. Silva, V.J. Trava-Airoldi, Y.W. Chung, Surf. Coat. Technol. 205 (2011) 3703-3707.

[23] N. Vidakis, A. Antoniadis, N. Bilalis, J. Mater. Process. Technol. 143-144 (2003) 481-485.

[24] A. Meena, M.E. Mansori, Wear 271 (2011) 2412-2416. 